(c) American Dairy Science Association, 2006.

\title{
Extending the Potential of Evaporative Cooling for Heat-Stress Relief
}

\author{
A. Berman \\ Department of Animal Science, Hebrew University, Rehovot 76100, Israel
}

\begin{abstract}
Factors were analyzed that limit the range of environmental conditions in which stress from heat may be relieved by evaporative cooling in shaded animals. Evaporative cooling reduces air temperature (Ta), but increases humidity. Equations were developed to predict Ta reduction as a function of ambient temperature and humidity and of humidity in cooled air. Predictions indicated that a reduction of $\mathrm{Ta}$ becomes marginal at humidities beyond $45 \%$. A reduction of Ta lessens with rising ambient Ta. The impact of increasing humidity on respiratory heat loss (Hre) was estimated from existing data published on Holstein cattle. Respiratory heat loss is reduced by increased humidity up to $45 \%$, but is not affected by higher humidity. Skin evaporative and sensible heat losses are determined not only by the humidity and temperature gradient, but also by air velocity close to the body surface. At higher Ta, the reduction in sensible heat loss is compensated for by an increased demand for Hre. High Hre may become a stressor when panting interferes with resting and rumination. Effects of temperature, humidity, air velocity, and body surface exposure to free air on Hre were estimated by a thermal balance model for lactating Holstein cows yielding $35 \mathrm{~kg} / \mathrm{d}$. The predictions of the simulations were supported by respiratory rate observations. The Hre was assumed to act as a stressor when exceeding $50 \%$ of the maximal capacity. When the full body surface was exposed to a $1.5 \mathrm{~m} / \mathrm{s}$ air velocity, humidity (15 to $75 \%$ ) had no significant predicted effect on Hre. For an air velocity of $0.3 \mathrm{~m} / \mathrm{s}$, Hre at $50 \%$ of the maximum rate was predicted at $34,32.5$, and $31.5^{\circ} \mathrm{C}$ for relative humidities of 55,65 , and $75 \%$, respectively. Similar results were predicted for an animal with twothirds of its body surface exposed to $1.5 \mathrm{~m} / \mathrm{s}$ air velocity. If air velocity was reduced for such animals to $0.3 \mathrm{~m} /$ $\mathrm{s}$, the rise in Hre was expected to occur at approximately $25^{\circ} \mathrm{C}$ and $50 \%$ relative humidity. Maximal rates of Hre were estimated at 27 to $30^{\circ} \mathrm{C}$ when ambient humidity was $55 \%$ relative humidity and higher. High humidity
\end{abstract}

Received March 16, 2006.

Accepted May 2, 2006.

E-mail: berman@agri.huji.ac.il may stress animals in evaporative cooling systems. Humidity stress may be prevented by a higher air velocity on the body surface of the animal, particularly in sheltered areas in which the exposed body surface is reduced, such as mangers and stalls. This may extend the use of evaporative cooling to less dry environments. Key words: heat stress, evaporative cooling, respiratory stress

\section{INTRODUCTION}

The alleviation of heat stress in cattle by evaporation of water enhanced by forced-air movement was examined $60 \mathrm{yr}$ ago (Seath and Miller, 1948), but the technologies required for its implementation in dairy systems were not available at that time. Subsequent attempts to reduce heat stress targeted shelter design to reduce the radiant heat load (Kelly et al., 1950), followed by use of forced ventilation (Ittner et al., 1957). Evaporative cooling was later suggested (Wiersma and Stott, 1966), and its use as forced-ventilated wet pads was subsequently examined, but results were inconsistent (Brown et al., 1974). Later, systems were developed that sprayed small water droplets into the air to evaporate and reduce air temperature (Ta). These systems were initially introduced in closed environments of glass houses (Landsberg et al., 1979), subsequently in poultry enclosures (Timmons and Baughman, 1983; Wilson et al., 1983), and only later in cattle housing (Ryan et al., 1992).

Analyses of evaporative cooling in enclosed environments were available in the late 1970s (Landsberg et al., 1979). Numerical optimization of mist-fog closed systems for livestock was carried out later, and its efficiency was estimated in terms of a temperature humidity index (THI; Huhnke et al., 2004). The THI assigns equal weights to temperature and humidity, but does not reflect their relative effects on cattle. The THI does not account for the effects of air velocity on heat loss (Berman, 2004, 2005).

The range of conditions in which evaporative cooling is effective and the mode of operation of evaporative cooling in dairy systems are not well defined. This report presents an approach to identify conditions in which evaporative cooling may be efficiently used for the relief of heat stress in dairy cattle. 


\section{METHODS}

\section{Study Layout}

The environmental conditions in which evaporative cooling may relieve heat stress in shaded cattle were examined in several steps: 1) Changes in ambient conditions produced by evaporative cooling are presently estimated for individual cases by using a psychrometric chart. Knowing the relationships between ambient conditions and the conditions created by evaporative cooling would make it possible to estimate the potential for heat stress relief by evaporative cooling in different environments. Deriving the relationships from repeated solutions with the psychrometric chart is time consuming. Enthalpy calculations were used to produce numerical solutions to the relations between ambient temperature and humidity and between cooled air temperature (Tc) and humidity. These may be used to predict the impact of evaporative cooling in various shaded environments. 2) The reduction of Ta by evaporative cooling is associated with a rise in Tc humidity. A high humidity in Tc may reduce the capacity for evaporative heat loss via respiratory water loss and lessen the potential improvement in thermal balance by evaporative cooling. The impact of ambient humidity on respiratory water loss was estimated from published data, to examine whether a reduction in respiratory water loss with high humidity may set limits on evaporative cooling. 3) The lower temperature but higher humidity in evaporatively cooled air has complex effects. The higher humidity in Tc reduces skin evaporative heat loss. A reduction in skin heat loss (Hsk) because of high humidity may produce a greater demand for evaporative cooling from the respiratory tract and induce panting to the extent of stressing the animals. The lower Ta produced by evaporative cooling enhances skin convective heat loss. The impact of the latter on thermal balance depends on the velocity of air surrounding the animal and its exposed body surface. The combined effects of exposed body surface, air humidity, temperature, and velocity on the thermal state of the animal were solved using thermal balance simulations. 4) The thermal balance is highly sensitive to air velocity on the surface of the body. Presently, a wealth of information exists on air velocity undisturbed by the presence of obstructing bodies, that is, at a distance from the animals. This is a rather unlikely method for representing the velocity of air effective in convective heat loss from the body of animals. To clarify this matter, omnidirectional air velocity was measured close to the surface of the body of cows and was related to the undisturbed air velocity. 5) The predictive value of thermal balance simulations was examined by correlating the respiratory rates of cows in moderate to warm conditions with the respira- tory heat loss (Hre) predicted for the same conditions by the thermal balance model. Combining these results led to solutions that integrated the effects of Ta, humidity, and air velocity.

\section{Enthalpy Calculations}

A general solution to the relation between temperature and humidity in air may be attained by enthalpy calculations. The heat required for the transition of water from liquid to gas is derived from the surrounding air. The evaporation of water into the air (i.e., an increase in water enthalpy) is thus accompanied by a reduction in Ta (i.e., a decrease in air enthalpy). In evaporative cooling, the increase in water vapor enthalpy equals the decrease in air enthalpy. The conditions in which these changes are equal may be estimated by the equations for dry air and water vapor enthalpies (Monteith, 1973; Campbell, 1977):

$$
\mathrm{h}_{\mathrm{a}}=\mathrm{Ta} \times 1.01 \times \rho_{\mathrm{a}}
$$

and

$$
\mathrm{h}_{\mathrm{v}}=\mathrm{Ta} \times 1.88 \times \rho_{\mathrm{v}}+2,502 \times \rho_{\mathrm{v}},
$$

where Ta is the temperature of ambient air; $h_{a}$ and $h_{v}$ are dry air and water vapor enthalpies $(\mathrm{kJ} / \mathrm{kg})$, respectively; $\rho_{\mathrm{a}}$ and $\rho_{\mathrm{v}}$ are dry air and water vapor densities $\left(\mathrm{kg} / \mathrm{m}^{3}\right)$, respectively; 1.01 and 1.88 are the specific heat of dry air and water vapor (kJ/kg), respectively; and 2,502 is the latent heat of water $(\mathrm{kJ} / \mathrm{kg})$.

The conditions in which the increase in water vapor enthalpy equals the reduction in dry air enthalpy may be equated by combining Equations 1 and 2:

$$
\begin{gathered}
1.01 \times\left(\rho_{\mathrm{a}} \times \mathrm{Ta}-\rho_{\mathrm{ac}} \times \mathrm{Tc}\right)=1.88 \times\left(\rho_{\mathrm{vc}} \times \mathrm{Tc}\right. \\
\left.-\rho_{\mathrm{va}} \times \mathrm{Ta}\right)+2,502 \times\left(\rho_{\mathrm{vc}}-\rho_{\mathrm{va}}\right)
\end{gathered}
$$

where $\mathrm{Ta}$ and $\mathrm{Tc}$ are the temperature of ambient and cooled air, respectively; $\rho_{\mathrm{va}}$ and $\rho_{\mathrm{vc}}$ are the water vapor density in ambient and cooled air ( $\mathrm{kg} / \mathrm{kg}$ of dry air), respectively; and $\rho_{\mathrm{a}}$ and $\rho_{\mathrm{ac}}$ are the dry air density in ambient and cooled air ( $\mathrm{kg} / \mathrm{kg}$ of dry air), respectively.

The equations presented in Table 1 produce sea-level values for $\rho_{\mathrm{a}}, \rho_{\mathrm{ac}}, \rho_{\mathrm{va}}$, and $\rho_{\mathrm{vc}}$ at different temperatures. The latent heat of evaporation is affected little by temperature $\left(0.0024 \mathrm{MJ} / \mathrm{kg}\right.$ per $\left.{ }^{\circ} \mathrm{C}\right)$ and elevation $(0.65 \mathrm{MJ} /$ $\mathrm{kg}$ per $100 \mathrm{~m}$ of altitude; Monteith, 1973). In calculations of evaporative cooling of air, an ideal situation was assumed, namely, that all latent heat of evaporation was derived from the air.

It is difficult to provide a general solution to Equation 3 , because the temperatures of unmodified ambient $\mathrm{Ta}$ 
Table 1. Coefficients and equations used in the calculations of heat exchange between air and moisture

\begin{tabular}{llll}
\hline Item & Symbol & Value & Unit \\
\hline Air density $^{1}$ & $\rho_{\mathrm{a}}$ & $\mathrm{P} \times \mathrm{M} / \mathrm{R} \times \mathrm{T}$ (from gas laws) & $\mathrm{kg} / \mathrm{m}^{3}$ \\
Specific heat of air $^{2}$ & $\mathrm{c}_{\mathrm{a}}$ & 1.01 & $\mathrm{~kJ} / \mathrm{kg} \mathrm{per}^{\circ} \mathrm{C}$ \\
Saturation water vapor pressure $^{3}$ & $\mathrm{p}_{\mathrm{v}}$ & $\exp (52.57-(6790 / \mathrm{K})-5.028 \times \ln \mathrm{K})$ & $\mathrm{kPa}$ \\
Saturation water vapor density $^{4}$ & $\rho_{\mathrm{v}}$ & $217 \times \mathrm{p}_{\mathrm{v}} / \mathrm{K}($ from gas laws $)$ & $\mathrm{g} / \mathrm{m}^{3}$ \\
Specific heat of water vapor $^{2}$ & $\mathrm{c}_{\mathrm{v}}$ & 1.88 & $\mathrm{~kJ} / \mathrm{kg} \mathrm{per}{ }^{\circ} \mathrm{C}$ \\
Latent heat of vaporization & $\gamma$ & 2,502 & $\mathrm{~kJ} / \mathrm{kg}$ \\
Enthalpy of the air:vapor mixture & $\mathrm{h}_{\mathrm{av}}$ & $\left(1.01 \times \rho_{\mathrm{a}}+1.88 \times \rho_{\mathrm{v}}\right) \times \mathrm{Ta}+2502 \times \rho_{\mathrm{v}}$ & $\mathrm{kJ} / \mathrm{kg}$ \\
\hline
\end{tabular}

${ }^{1} \mathrm{P}=101.3 \mathrm{kPa} ; \mathrm{M}=29.0 \mathrm{~g} ; \mathrm{R}=8.31 \mathrm{~J} / \mathrm{mol} \times \mathrm{K} ; \mathrm{T}=$ temperature in $\mathrm{K}$.

${ }^{2}$ Page 220 in Monteith (1973).

${ }^{3}$ Page 22 in Campbell (1977).

${ }^{4}$ Page 6 in Monteith (1973).

and of Tc may vary independently of each other. An indirect solution was therefore adopted. The difference in dry air enthalpy $(\mathrm{kJ} / \mathrm{kg})$ between Ta and $\mathrm{Tc}\left(\mathrm{h}_{\mathrm{a}}\right.$ and $\mathrm{h}_{\mathrm{ac}}$, respectively) was computed for a range of Ta (28 to $45^{\circ} \mathrm{C}$ in $1^{\circ} \mathrm{C}$ increments), where each Ta was associated with a range of Tc values (lower than Ta by 4 to $14^{\circ} \mathrm{C}$ in $1^{\circ} \mathrm{C}$ increments). The difference in water vapor enthalpy between Ta and $T c\left(h_{v}\right.$ and $h_{v c}$, respectively) for each such combination was computed for a range of relative humidity values for $\mathrm{Ta}$ (10 to $70 \%$ in $5 \%$ increments) and for Tc (40 to $80 \%$ in $10 \%$ increments). This generated a total of approximately 18,000 sets of Ta, $\mathrm{Tc}, \mathrm{h}_{\mathrm{a}}, \mathrm{h}_{\mathrm{ac}}, \mathrm{h}_{\mathrm{v}}$, and $\mathrm{h}_{\mathrm{vc}}$ data. The differences in dry air and water vapor enthalpy between the Ta and Tc sets were calculated. In 95 cases the differences between dry air enthalpy and water vapor enthalpy was within $\pm 2.5 \%$ of the water vapor enthalpy. In these cases Tc approximated the wet bulb temperature. These 95 cases represented pairs of situations of temperature and humidity in ambient air and in cooled air [Ta and relative humidity (RH) in ambient air, and Tc and RH in cooled air (RHc), respectively] in which the reduction in dry air enthalpy during the evaporative cooling of air was close to the associated increase in water vapor enthalpy. The relations between these parameters were analyzed to provide numerical solutions for evaporative cooling.

\section{Impact of Humidity on Heat Loss}

The maintenance of body temperature stability demands that the difference between heat produced in the body and that dissipated by sensible and latent heat losses from the skin must be dissipated via the respiratory tract (Berman, 2005). This implies that rising Ta increase the demand for water evaporation from the respiratory tract. A depressive effect of $\mathrm{RH}$ on $\mathrm{Hsk}$ would increase the demand for Hre. Ambient humidity may thus have both direct and indirect effects on Hre.

\section{Impact of Humidity on Hre}

Respiratory response data for Holstein cows in climate chamber studies were used to predict the respiration rate $(\mathbf{R R})$, tidal volume $(\mathbf{V t})$, and expired Ta as a function of the Ta and RH (Stevens, 1981) for cows in first-phase panting. In this phase, the increase in Hre is attained by a rise in RR coupled with a decline in Vt. The equations produced in that study were

$$
\begin{gathered}
\mathrm{RR}=\mathrm{e}^{(2.966+0.0218 \times \mathrm{Ta}+0.00069 \times \mathrm{Ta} 2)} \\
\mathrm{Vt}=0.0189 \times \mathrm{RR}^{-0.463} \\
\mathrm{Tex}=17.0+0.3 \times \mathrm{Ta}+\mathrm{e}^{0.01611 \times \mathrm{RH}+0.0387 \times \mathrm{Ta}}
\end{gathered}
$$

where $\mathrm{RR}$ is the respiration rate (breaths/min), $\mathrm{Vt}$ is the tidal volume $\left(\mathrm{m}^{3} / \mathrm{breath}\right)$, and Tex is the temperature of expired air $\left({ }^{\circ} \mathrm{C}\right)$.

Equations 4 to 6 were used to estimate the hourly pulmonary ventilation rate $\left(\mathrm{m}^{3} / \mathrm{h}\right)$ and expired Ta. Respiratory water loss at different Ta and $\mathrm{RH}$ was computed, using Table 1 equations, for Ta ranging from 25 to $40^{\circ} \mathrm{C}$, in $2^{\circ} \mathrm{C}$ steps, and for $\mathrm{RH}$ ranging from 15 to $80 \%$, in $10 \%$ steps. This produced a data set that was used to analyze the effect of $\mathrm{RH}$ on Hre.

\section{Thermal Balance Simulations}

Increases in Ta reduce skin convective and radiant heat loss and increase the demand for skin evaporative heat loss. These constitute total Hsk. Evaporative cooling reduces the Tc but increases its RHc. Skin evaporative heat loss is affected by the surrounding $\mathrm{RH}$. The Hsk is relative to the body surface exposed to air and to the velocity of air movement on the exposed body surface. Cattle spend a large part of their day recumbent and also huddle, which reduces the exposed body surface by 20 to $50 \%$ and consequently reduces Hsk. A 
smaller Hsk increases the demand for Hre. Air temperature and humidity in the respiratory tract are determined not only by the Ta and RH of incoming air but also by the breathing rate and Vt. The latter are modulated by the thermal state. Evaporative cooling increases the moisture content of cooled air, which reduces the capacity for skin and respiratory evaporative heat loss. The interactions between $\mathrm{RH}, \mathrm{Ta}$, and airvelocity-exposed body surface effects on respiratory and Hsk are complex, but may be estimated by thermal balance simulations.

A cattle thermal balance simulation model, modified to suit the summer-adapted Holstein cow (McGovern and Bruce, 2000; Berman, 2005), was used to estimate Hre and Hsk for a cow of $600 \mathrm{~kg}$ of BW and $35 \mathrm{~kg} / \mathrm{d}$ of milk yield, values that represent cows in the higher producing herds. The thermal balance model modifies $\mathrm{Vt}, \mathrm{RR}$, and sensible and latent Hsk for the effects of ambient conditions ( $\mathrm{Ta}$, velocity, and $\mathrm{RH}$; McGovern and Bruce, 2000). Metabolic heat production was estimated at $931 \mathrm{~W}$, hair coat depth at $3 \mathrm{~mm}$, radiant temperature at $3^{\circ} \mathrm{C}$ above $\mathrm{Ta}$, and skin moisture loss at $220 \mathrm{~g} / \mathrm{m}^{2}$ per $\mathrm{h}$. These values were chosen because they represent Holstein cows kept in loose housing systems in summer and because the effects of different metabolic heat production and hair-coat-depth values on responses to environmental heat were estimated previously (Berman, 2004; Berman, 2005).

Simulations were run to estimate Hre and Hsk for Ta ranging from 25 to $40^{\circ} \mathrm{C}$ (in $1.25^{\circ} \mathrm{C}$ increments), and $\mathrm{RH}$ ranging from 15 to $75 \%$ (in $10 \%$ increments) when the full body surface or two-thirds of it was exposed to air velocities of 0.3 or $1.5 \mathrm{~m} / \mathrm{s}$. The reduced body surface simulates the effects of huddling or of lying, in which the body surface exposed to moving air is reduced to about $66 \%$. The Hre and Hsk were expressed in heat loss per cow units (W/cow). In total, 350 simulations were carried out. The data set produced by these simulations was used to analyze the effects of $\mathrm{Ta}, \mathrm{RH}$, air velocity, and exposed body surface on Hre.

\section{Air Velocity Close to the Body Surface}

Air velocity has marked effects on Hsk and is an important component of thermal balance. The velocity of wind, measured in the free air above the cow's back, is not likely to represent the velocity effective in animal heat loss. The latter is determined by the velocity in proximity to the body surface. Air velocity was measured at $1 \mathrm{~m}$ above the back and at $10 \mathrm{~cm}$ above the body surface at sites located at $45^{\circ}$ around the midbody of 15 standing cows. It was measured by a sensitive omnidirectional thermocouple anemometer $( \pm 0.05 \mathrm{~m} /$ s, model B-27; Hastings-Raydist Inc., Hampton VA).
Measurements were carried out while the cows were standing with their heads in stanchions distanced 85 $\mathrm{cm}$ apart. Attempts to carry out such measurements in cows free to move were unsuccessful, because the cows moved when approached.

\section{$R R$ in Cows}

The predictive value of the model was further examined by comparing the respiratory responses of Holstein cows to given ambient conditions with responses predicted by the model for the same conditions. These data are part of a larger study of the respiratory and behavioral responses of dairy cows. The cows were milked 3 times daily, with a daily milk yield of $34.8 \pm 2.2$ (SD) $\mathrm{kg}$ and at $204 \pm 22(\mathrm{SD}) \mathrm{DIM}$. The cows $(\mathrm{n}=73)$ were kept on deep straw bedding, in the shade of an open, loose housing system providing $14 \mathrm{~m}^{2} / \mathrm{cow}$, in which radiant temperature was about $3^{\circ} \mathrm{C}$ above Ta. The cows were offered a fresh TMR twice daily. Air movement was maintained by fans located $4 \mathrm{~m}$ apart along the feeding line. During the higher Ta period, a regular breeze, 1.5 to $2 \mathrm{~m} / \mathrm{s}$ air velocity in free air, prevailed from 1000 to $1600 \mathrm{~h}$. During this period, the cows were cooled by wetting and forced ventilation for $0.5 \mathrm{~h}$ before each milking. Respiratory rate was determined by flank movements over 30 -s periods in 10 standing and 10 resting randomly selected cows, at 2 -h intervals between 0900 and $1300 \mathrm{~h}$ on $16 \mathrm{~d}$ between the spring and fall of $1 \mathrm{yr}$. Ambient conditions were determined in free air using a multifunction instrument (model 451; Testo $\mathrm{AG}$, Lenzkirch, Germany). Air temperature $\left( \pm 0.1^{\circ} \mathrm{C}\right)$, air velocity by miniature vane anemometer $( \pm 0.4 \mathrm{~m} / \mathrm{s})$, and $\mathrm{RH}( \pm 2 \%)$ were measured at the start and end of each RR measurement. The RR observed were correlated with the Hre predicted for these environmental conditions by the thermal balance simulation model.

\section{RESULTS}

\section{Enthalpy Calculations}

The 91 sets of Ta, Tc, $\mathrm{RH}$, and $\mathrm{RHc}$ data associated with changes in enthalpies of dry air and water vapor that were within $2.5 \%$ of each other served to approximate the relations between $\mathrm{Ta}, \mathrm{Tc}, \mathrm{RH}$, and $\mathrm{RHc}$ over the Ta range of 28 to $45^{\circ} \mathrm{C}$ and $\mathrm{RH}$ range of 10 to $70 \%$. The Tc was approximated by the following regression equation:

$$
\begin{aligned}
\mathrm{Tc}=1.9+ & 0.76 \times \mathrm{Ta}+0.30 \times \mathrm{RH}-0.18 \\
& \times \mathrm{RHc}\left(\mathrm{R}^{2}=0.985\right)
\end{aligned}
$$


The reduction in Ta expected at given $\mathrm{RH}$ and $\mathrm{RHc}$ conditions was approximated by the following regression equation:

$$
\begin{aligned}
\mathrm{dTa} & =-1.9+0.24 \times \mathrm{Ta}-0.30 \times \mathrm{RH} \\
& +0.18 \times \mathrm{RHc}\left(\mathrm{R}^{2}=0.971\right)
\end{aligned}
$$

where

$$
\mathrm{dTa}=\mathrm{Ta}-\mathrm{Tc}\left({ }^{\circ} \mathrm{C}\right) .
$$

The $\mathrm{R}^{2}$ values of the two regressions (Equations 7 and 8) are high enough to give them a satisfactorily reliable predictive potential. The regressions estimate the effects of RH and of RHc on Tc and dTa. A 10percentage-unit increase in $\mathrm{RH}$ lessens the reduction in Tc by about $3^{\circ} \mathrm{C}$. This might be counteracted by increasing humidity in the cooled air. But such an attempt would compensate for only about $60 \%$ of the effect of $\mathrm{RH}$, as indicated by the ratio of the coefficients of $\mathrm{RHc}$ and $\mathrm{RH}$ (i.e., 0.18:0.30). A $1^{\circ} \mathrm{C}$ increase in Ta is accompanied by an increase of only $0.24^{\circ} \mathrm{C}$ in the reduction of Ta attained by evaporative cooling. This indicates a reduction in the heat stress relief potential of evaporative cooling with rising Ta. At a $\mathrm{RH}$ of $15 \%$, the reduction in Ta by evaporative cooling is in the range of 13 to $15^{\circ} \mathrm{C}$, a significant improvement in potential convective heat loss (Table 2). The reduction in Ta declines steeply with rising $\mathrm{RH}$. In the 32 to $42^{\circ} \mathrm{C}$ Ta range at $45 \% \mathrm{RH}$, the reduction in Ta becomes 30 to $40 \%$ of that at $15 \%$ $\mathrm{RH}$. The decline in Ta by evaporative cooling therefore becomes questionable at $\mathrm{RH}$ over $45 \%$, even at high Ta. This reduction in the impact of evaporative cooling may be counteracted by increasing air velocity, a convective heat loss factor not accounted for by enthalpy calculations.

\section{Hre}

The data set produced from respiratory functions at different $\mathrm{Ta}$ and $\mathrm{RH}$ were used to estimate the effects of ambient conditions on respiratory moisture loss. These effects were approximated by the following equation:

Table 2. Predicted reduction of air temperature by evaporative cooling $^{1}$ as function of outdoor temperature and humidity, when cooled air is at $65 \%$ relative humidity

\begin{tabular}{llllll}
\hline & \multicolumn{5}{c}{ Outdoor relative humidity $(\%)$} \\
\cline { 2 - 6 } Outdoor air temperature $\left({ }^{\circ} \mathrm{C}\right)$ & 15 & 25 & 35 & 45 & 55 \\
\hline 34 & 13.3 & 10.1 & 6.9 & 3.8 & 0.6 \\
38 & 14.3 & 11.1 & 7.9 & 4.8 & 1.6 \\
42 & 15.2 & 12.1 & 8.9 & 5.7 & 2.6 \\
\hline
\end{tabular}

${ }^{1}$ From Equation 8.

$$
\begin{gathered}
\mathrm{Rwl}=0.41-0.02 \times \mathrm{Ta}+0.0005 \times \mathrm{Ta}^{2} \\
-0.004 \times \mathrm{RH}+0.00004 \times \mathrm{RH}^{2}\left(\mathrm{R}^{2}=0.979\right)
\end{gathered}
$$

where Rwl is respiratory water loss $\left(\mathrm{g} \mathrm{h}^{-1}\right)$ and $\mathrm{RH}$ is ambient relative humidity (\%).

Respiratory water loss increased with rising Ta and declined with rising $\mathrm{RH}$, with no interaction between the effects of Ta and $\mathrm{RH}$ (Figure 1 ). At $40^{\circ} \mathrm{C}$ at a $\mathrm{RH}$ of $15 \%$, Rwl was $33 \%$ larger than at $45 \% \mathrm{RH}$. The maximal impact of $\mathrm{RH}$ was reached at about $40 \% \mathrm{RH}$, at which the Rwl was indistinguishable from those at 45,50 , and $60 \% \mathrm{RH}$. This implies not only a depressive effect of $\mathrm{RH}$ on $\mathrm{Rwl}$, but also that increasing the $\mathrm{RH}$ beyond $40 \%$ would not further affect the Rwl.

\section{Thermal Balance}

When the body temperature is stable and Hsk is near maximal, Hre reflects the additional Hre required to maintain the stability of body temperature. The higher the Ta, the more likely it is that a moderate $\mathrm{Tc}$ is attained at the cost of a high $\mathrm{RH}$. Stress is expected to appear when the $\mathrm{RH}$ reduces the evaporative component of Hsk to the extent that it elicits a marked demand for Hre. The interactions between effects of Ta, $\mathrm{RH}$, air velocity, and the proportion of exposed body surface on Hre were estimated from the outputs of the thermal balance simulations.

The estimates of the thermal balance simulations suggest that when the full body surface is exposed to a $1.5 \mathrm{~m} / \mathrm{s}$ air velocity, $\mathrm{RH}$ (15 to $75 \%$ ) has no significant effect on Hre (data not shown). A low air velocity reduces the convective and evaporative heat loss from the body surface and increases the impact of the effects of $\mathrm{RH}$ on Hsk. At an air velocity of $0.3 \mathrm{~m} / \mathrm{s}$ the Ta at which the Hre starts to rise above its basal values is reduced by 1.2 to $1.5^{\circ} \mathrm{C}$ for increments of $10 \%$ units in $\mathrm{RH}$ (Figure $2 \mathrm{~A}$ ). At an ambient 55\% $\mathrm{RH}$, a rise in Hre to $50 \%$ of the maximum rate is estimated to occur at $34^{\circ} \mathrm{C}$. At 65 and $75 \% \mathrm{RH}$, similar rates of Hre are expected to appear at 32.5 and $31^{\circ} \mathrm{C}$, respectively. These set tentative limits on the extent to which RH may be increased to reduce Tc by evaporative cooling for a standing animal exposed to $0.3 \mathrm{~m} / \mathrm{s}$ air velocity.

A reduction in exposed body surface reduces the total Hsk, and therefore increases the demand for Hre as well as its sensitivity to $\mathrm{RH}$ and the velocity effects on Hsk. For an animal in which only $66 \%$ of its body surface is exposed to Ta at a $1.5 \mathrm{~m} / \mathrm{s}$ velocity, increases in Hre to $50 \%$ of its maximum are estimated to occur at $31.5^{\circ} \mathrm{C}$ if the $\mathrm{RH}$ is $75 \%$, at $33^{\circ} \mathrm{C}$ if the $\mathrm{RH}$ is $65 \%$, and at $34^{\circ} \mathrm{C}$ if the $\mathrm{RH}$ is $55 \%$ (Figure 2B). If a similar animal is exposed to a $0.3 \mathrm{~m} / \mathrm{s}$ velocity (Figure $2 \mathrm{C}$ ), the increase 


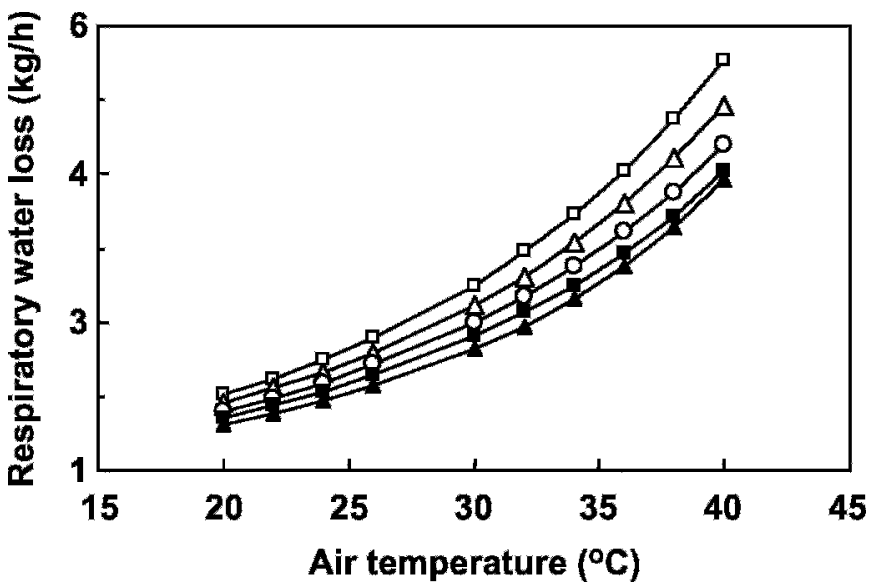

Figure 1. Water loss from the respiratory tract $(\mathrm{kg} / \mathrm{h}$, as predicted by Equations 4 to 6 and the equations in Table 1) as a function of ambient temperature and relative humidity $(\square, 15 \% ; \triangle, 25 \% ; \bigcirc, 35 \%$; $\boldsymbol{\square}, 45 \% ; \boldsymbol{\Lambda}, 55 \%$ ) when cooled air is at $65 \%$ relative humidity.

in Hre is expected to occur at about $25^{\circ} \mathrm{C}$ and $50 \% \mathrm{RH}$, and the maximal rates of Hre are estimated to occur at 27 to $30^{\circ} \mathrm{C}$ when the $\mathrm{RH}$ is $55 \%$ and higher. The simulations also predicted a moderate effect of $\mathrm{RH}$ on maximal Hre. Increasing the $\mathrm{RH}$ from 55 to $75 \%$ reduced the maximal Hre by 15 to $20 \%$.

\section{Air Velocity Proximal to the Body Surface}

The cows were of a similar age and BW, in their second to fourth lactation, and in an average body condition for lactating cows. The cows were standing with their heads in stanchions and were perpendicularly oriented toward the wind. Mean $( \pm \mathrm{SEM})$ air velocity at 1 $\mathrm{m}$ above the back of the cows was $0.9 \pm 0.24 \mathrm{~m} / \mathrm{s}$, ranging from 0.5 to $1.4 \mathrm{~m} / \mathrm{s}$. This variation in wind velocity is typical for most wind conditions. Mean air velocity at $10 \mathrm{~cm}$ above the body surface was $0.40 \pm 0.02 \mathrm{~m} / \mathrm{s}$. The data of practically concomitant air velocities above the cows and between the cows were used to estimate the relationship between air velocity in free air and that prevailing in proximity of the body surface. This relation is represented by the regression

$$
\mathrm{Vs}=0.113+0.3 \times \mathrm{Va}\left(\mathrm{R}^{2}=0.847\right),
$$

where Vs is air velocity in proximity of the body surface and $\mathbf{V a}$ is air velocity at $1 \mathrm{~m}$ above the back.

The residuals of the regression were randomly distributed, with no indication of a nonlinear relation between $\mathrm{Va}$ and $\mathrm{Vs}$. The $\mathrm{Vs}$ was in the 0.3 to $0.4 \mathrm{~m} / \mathrm{s}$ range, with the exception of the higher $\mathrm{Vs}$ on the upper body side facing the wind (Figure 3). The distribution of air velocity around the body was almost symmetrical,

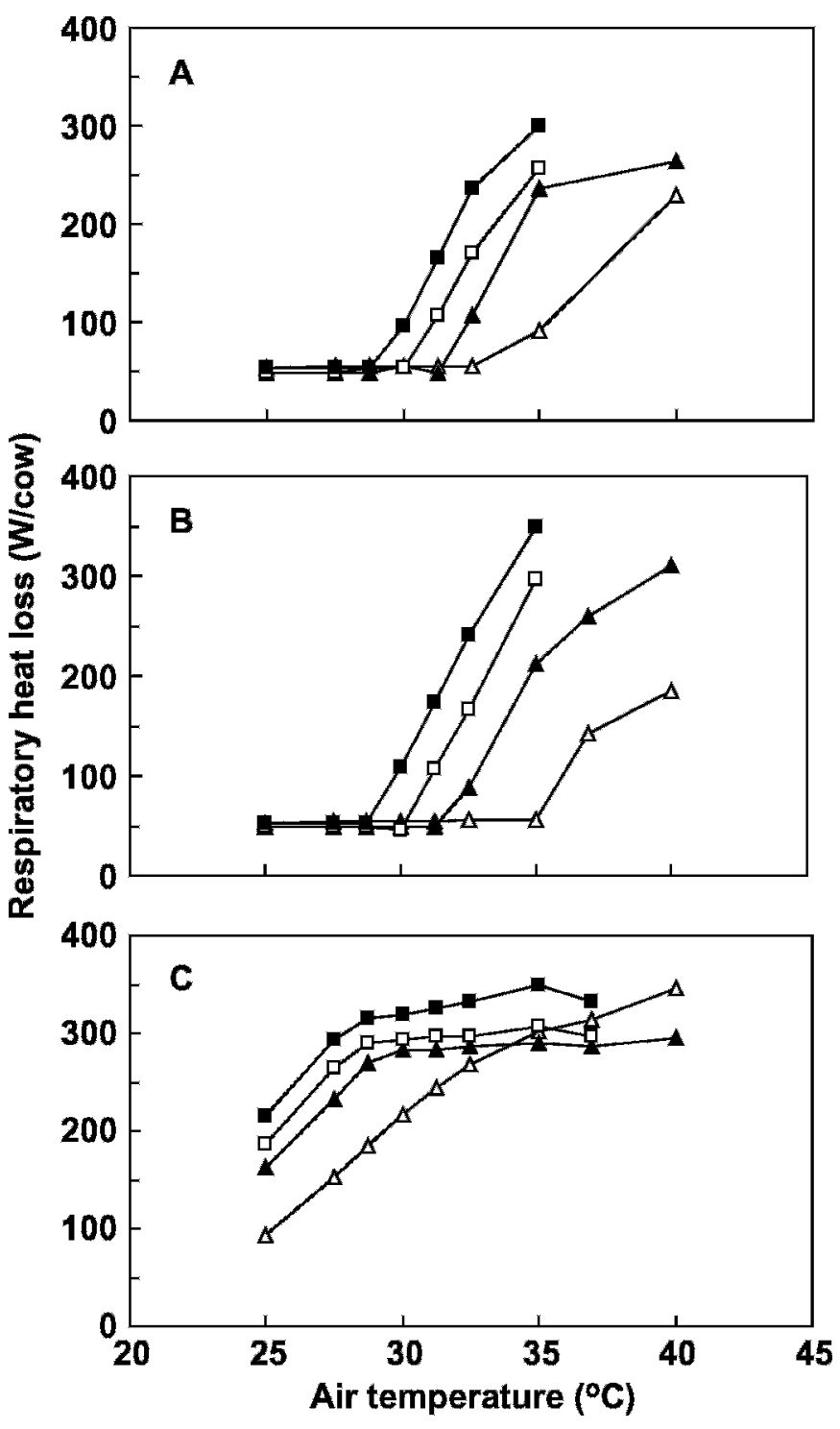

Figure 2. Heat loss from the respiratory tract (W/cow), as predicted from the thermal balance model, as a function of ambient temperature and relative humidity $(\triangle, 30 \% ; \mathbf{\Delta}, 55 \% ; \square, 65 \% ; \mathbf{\square}$, $75 \%$ ): A) for a cow standing with the full body surface exposed to 0.3 $\mathrm{m} / \mathrm{s}$ air velocity; B) for a recumbent cow with two-thirds of the body surface exposed to $1.5 \mathrm{~m} / \mathrm{s}$ air velocity; and C) for a recumbent cow with two-thirds of the body surface exposed to $0.3 \mathrm{~m} / \mathrm{s}$ air velocity.

with a slight distortion at $45^{\circ}$, the side of the body facing the wind. An effect of wind was not observed at greater angles.

\section{$\boldsymbol{R} \boldsymbol{R}$}

Mean ambient conditions during RR measurements $( \pm \mathrm{SEM})$ were $27.6 \pm 0.2^{\circ} \mathrm{C}, 52 \pm 0.4 \mathrm{RH}$, and $0.8 \pm 0.02$ $\mathrm{m} / \mathrm{s}$. The ranges in ambient conditions were 15 to $34.9^{\circ} \mathrm{C}, 20$ to $67 \% \mathrm{RH}$, and 0.3 to $2.3 \mathrm{~m} / \mathrm{s}$. These reflect 


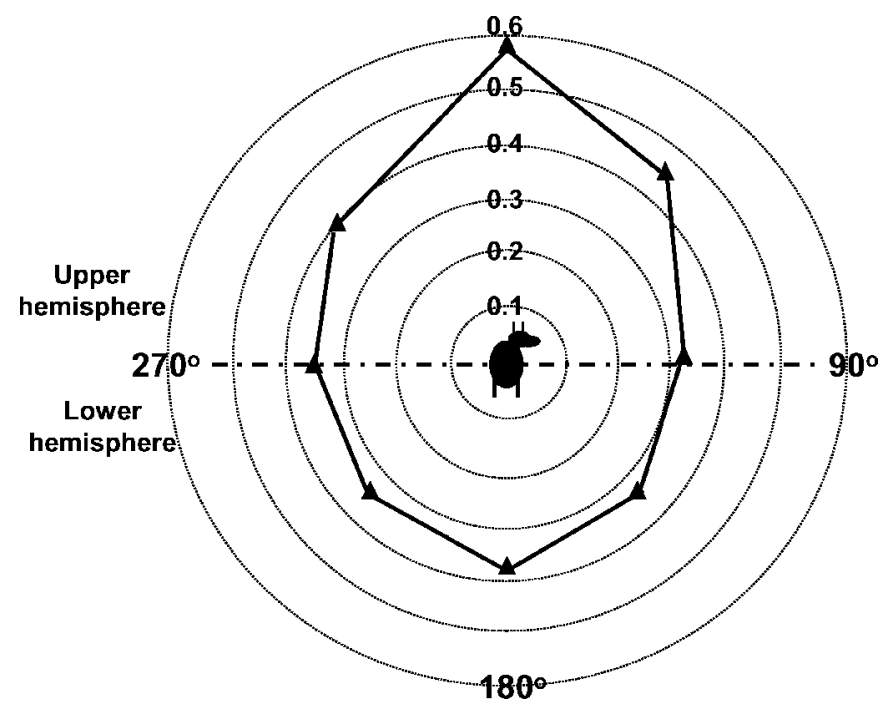

Figure 3. Distribution of mean omnidirectional air velocity at 10 $\mathrm{cm}$ above the body surface at different angles around the body of 15 standing cows, when the mean air velocity $( \pm$ SEM) at $1 \mathrm{~m}$ above the back of the cow is $0.9 \pm 0.07 \mathrm{~m} / \mathrm{s}$.

ambient conditions in the shade at $1.5 \mathrm{~m}$ above ground in the free air outside the housing. In total, $390 \mathrm{RR}$ measurements were taken on 16 observation days. The mean $R R$ was $63.7 \pm 1.0$, ranging from 24 to 132 breaths/min.

The relationship between $R R$ and ambient conditions was best described by the following regression:

$$
\begin{gathered}
\mathrm{RR}=351.5-8.86 \times \mathrm{Ta}+0.053 \times \mathrm{Ta}^{2}-9.36 \times \mathrm{RH} \\
\quad+0.054 \times \mathrm{RH}^{2}+0.17 \times \mathrm{Ta} \times \mathrm{RH}\left(\mathrm{R}^{2}=0.571\right) .
\end{gathered}
$$

Ambient air velocity, as measured at a height of 1.5 $\mathrm{m}$ above ground in the free air, did not have significant effects on RR.

\section{Predicted and Observed Respiratory Values}

Correlations between RR observed and Hre predicted by the thermal balance model may provide an additional validation of the thermal balance model. Respiratory rates were in the range within which $\mathrm{RR}$ is linearly related to Hre (McArthur, 1987). Thermal balance simulations were carried out for full and reduced body surface exposed (representing standing and recumbent cows) at the average Ta and RH during the RR measurements. As previously indicated, air velocities measured in free air are not likely to represent the Vs of the cows. The thermal balance simulations were thus carried out for air velocities of 0.2 to $1.2 \mathrm{~m} / \mathrm{s}$. Correlations were calculated between Hre predicted by the thermal balance model at the different $\mathrm{Va}$ and $\mathrm{RH}$ observed on these days. It was presumed that if the thermal balance model predictions were close to real-life situations, the correlations would be the greatest at Vs.

The correlations between predicted Hre and observed $R R$ declined at air velocities higher than $0.3 \mathrm{~m} / \mathrm{s}$. The correlations were higher when a reduced body surface was assumed. The correlations between predicted Hre and RR were the highest at $\mathrm{Va}$ of $0.2 \mathrm{~m} / \mathrm{s}$ for the full body surface ( $\mathrm{r}=0.75, P<0.05)$, and at $\mathrm{Va}$ of $0.3 \mathrm{~m} / \mathrm{s}$ for the reduced body surface $(\mathrm{r}=0.97, P<0.01)$.

\section{DISCUSSION}

The changes in Ta that occur during evaporative cooling are usually obtained from a psychrometric chart. If a large bulk of data must be obtained, the time required for its acquisition becomes prohibitive. A mathematical model of the psychrometric chart had been presented in the past (Brooker, 1967). The model produced 17 equations for psychrometric variables (in BTU units), and if any 2 of these variables were provided, the others could be calculated. The approach presented here was to directly target combinations of ambient conditions in which a change in the enthalpy of water vapor is close to or equals that in the dry air. The approach was based on equations derived from gas laws and on the selection of cases in which changes in dry air and water vapor enthalpy were equal or close to equal. The latter data set was used to produce 2 equations, neither of which was previously available, to our knowledge. These equations (Equations 7 and 8) estimate Tc and the reduction in $\mathrm{Ta}$ attainable by evaporative cooling as a function of $\mathrm{Ta}, \mathrm{RH}$, and RHc. In ideal conditions of adiabatic changes, an increase of 10 percentage units in $\mathrm{RH}$ lessens by $3.2^{\circ} \mathrm{C}$ the reduction in $\mathrm{Ta}$ attainable by evaporative cooling. Only approximately $50 \%$ of this effect may be compensated for by a corresponding increase in RHc. Equations 7 and 8 represent ideal physical changes, and may serve to evaluate evaporative cooling systems (Bottcher et al., 1991). According to these equations, the reduction in Ta by evaporative cooling at RH over $45 \%$ (with RHc maintained at 65\%) becomes 30 to $40 \%$ of that in dry environments, even at high Ta. Such equations indicate the expected changes in conditions created by evaporative cooling but do not estimate the responses of animals. The latter are determined by the interactions among animals and the components of the environment.

For instance, greater reductions in Ta might be attained by allowing a higher RHc. However, a high RH might impair the Hre and Hsk and reduce the capacity to maintain thermal stability. The effect of $\mathrm{RH}$ on $\mathrm{Rwl}$ was estimated by empirical equations derived from a data set on Holstein cattle in controlled conditions (Ste- 
vens, 1981). Respiration rates in the latter study were highly correlated $(r=0.99)$ with the $R R$ observed in this study. The increase in Rwl with Ta was reduced by the rising $\mathrm{RH}$, and a maximal impact of $\mathrm{RH}$ was reached at about $40 \% \mathrm{RH}$. Higher $\mathrm{RH}$ did not further reduce the respiratory response to Ta. These predictions imply that $\mathrm{RH}$ of 70 to $80 \% \mathrm{RHc}$ prevailing in environments cooled by evaporative cooling (Hahn and Osburn, 1970; Frazzi et al., 2002) are not likely to be a factor markedly affecting the Rwl. This does not account for effects of $\mathrm{RH}$ on skin evaporative loss or for effects of exposed body surface and air velocity on heat exchange.

The body surface exposed to moving air is reduced when cows are huddling, as well as when cows adopt a recumbent posture during resting or rumination. Mature Holstein cows in stall housing systems spend about $15 \mathrm{~h} / \mathrm{d}$ lying, and the duration and frequency of lying probably are indicators of cow comfort (Haley et al., 2000). A smaller body surface reduces both the convective and the evaporative components of Hsk. The time spent lying was reduced in cows exposed to heat stress (Frazzi et al., 2000). Ambient temperature had a negative impact on the percentage of cows lying (Shultz, 1984; Overton et al., 2002). Higher standing values were associated with higher RR and body temperatures (Frazzi et al., 2000). Spray cooling of lying cows increased their lying time (Hillman et al., 2005). These support the contention, brought here, that a lying cow is more sensitive to heat stress than a standing cow. Respiratory heat loss is recruited when the Hsk is insufficient to maintain thermal stability. A high demand for Hre may, by itself, be a stressing factor because it reduces the time spent lying.

These generalizations are supported by thermal balance predictions, namely, that $\mathrm{RH}$ up to $75 \%$ have no estimable effect on Hre when the full body surface is exposed to a $1.5 \mathrm{~m} / \mathrm{s}$ air velocity. In contrast, when the full body surface is exposed to a $0.3 \mathrm{~m} / \mathrm{s}$ air velocity, the Hre is recruited to more than $50 \%$ of its maximal capacity, and its recruitment is earlier and steeper at $45 \% \mathrm{RH}$ and beyond. If $66 \%$ of the body surface is exposed, at a $1.5 \mathrm{~m} / \mathrm{s}$ air velocity the Hre becomes similar to that when the full body surface is exposed to a 0.3 $\mathrm{m} / \mathrm{s}$ air velocity. Responses are further aggravated when the exposed body surface is limited to $66 \%$ and air velocity is low. If the $\mathrm{RH}$ is low, the Hre rises continuously with rising $\mathrm{Ta}$ above $25^{\circ} \mathrm{C}$. If the $\mathrm{RH}$ is $55 \%$ and above, the Hre reaches a plateau at Ta below $30^{\circ} \mathrm{C}$, and the plateau is reduced by rising $\mathrm{RH}$. These indicate that the predicted response to $\mathrm{RH}$ depends not only on $\mathrm{Ta}$, but also on Vs and Va. The simulations suggest that evaporative cooling may be effective in relieving heat stress at $\mathrm{RH}$ beyond those predicted by enthalpy calculations if high air velocity is used to enhance skin evaporative and convective heat loss. These results are consistent with Hsk conceived as a simultaneous transfer of heat and mass, in which both dry and latent heat loss are similarly modified by air velocity (Arkin et al., 1991; Kimmel et al., 1991).

The velocity of air relevant to heat exchange is Vs. Airflow at $10 \mathrm{~cm}$ above the body surface was approximately 0.3 to $0.4 \mathrm{~m} / \mathrm{s}$, one-third of that observed in free air above the animals. The correlations between predicted Hre and RR were the highest at Vs. These support the relevance of thermal balance outputs to real-life responses. The higher correlation in recumbent animals is probably due to a smaller variability between animals in airflow over the exposed body surface.

In conclusion, the results suggest that the range of environmental conditions within which evaporative cooling is efficient may be markedly extended if air velocity in the proximity of the animals is in the 1 to $1.5 \mathrm{~m} / \mathrm{s}$ range. Also, the evaporative cooling system should not target uniform conditions in the housing space. A higher benefit may be expected from systems in which lower Ta and higher air velocity prevail in the resting area. Standing animals may attain comfort at high $\mathrm{RH}$, provided air velocity is high. These may be attained by controlling the distribution of water, droplet dimensions, their path in the housing space, and air velocity (Singletary et al., 1996). Optimizing evaporative cooling requires a more complex, but attainable, control system. Such a system may extend the feasibility of evaporative cooling into less dry environments.

\section{REFERENCES}

Arkin, H., E. Kimmel, A. Berman, and D. Broday. 1991. Heat transfer properties of dry and wet furs of dairy cows. Trans. ASAE $34: 2551-2558$.

Berman, A. 2004. Tissue and external insulation estimates and their effects on prediction of energy requirements and of heat stress. J. Dairy Sci. 87:1400-1412.

Berman, A. 2005. Estimates of heat stress relief needs for Holstein dairy cows. J. Anim. Sci. 83:1377-1384.

Bottcher, R. W., G. R. Baughman, R. S. Gates, and M. B. Timmons. 1991. Characterizing efficiency of misting systems for poultry. Trans. ASAE 34:586-590.

Brooker, D. B. 1967. Mathematical model of the psychrometric chart. Trans. ASAE 10:558-560.

Brown, W. H., J. W. Fuquay, W. H. McGee, and S. S. Iyengar. 1974. Evaporative cooling for Mississippi dairy cows. Trans. ASAE 17:513-515.

Campbell, G. S. 1977. An Introduction to Environmental Biophysics. Springer-Verlag, New York, NY.

Frazzi, E., L. Calamari, and F. Calegari. 2002. Productive response of dairy cows to different cooling systems. Trans. ASAE 45:396-405.

Frazzi, E., L. Calamari, F. Calegari, and L. Stefanini. 2000. Behavior of dairy cows in response to different barn cooling systems. Trans. ASAE 43:387-394.

Hahn, L. R., and D. D. Osburn. 1970. Feasibility of evaporative cooling for dairy cattle based on expected production losses. Trans. ASAE 13:289-294. 
Haley, D. B., J. Rushen, and A. M. d. Passille. 2000. Behavioural indicators of cow comfort: Activity and resting behaviour of dairy cows in two types of housing. Can. J. Anim. Sci. 80:257-263.

Hillman, P. E., C. N. Lee, and S. T. Willard. 2005. Thermoregulatory responses associated with lying and standing in heat-stressed cows. Trans. ASAE 48:795-801.

Huhnke, R. L., L. C. McCowan, G. M. Meraz, S. L. Harp, and M. E. Payton. 2004. Using evaporative cooling to reduce the frequency and duration of elevated temperature-humidity indices in Oklahoma. Appl. Eng. Agric. 20:95-99.

Ittner, N. R., C. F. Kelly, and T. E. Bond. 1957. Cooling cattle by mechanically increasing air movement. J. Anim. Sci. 16:732-738.

Kelly, C. F., T. E. Bond, and N. R. Ittner. 1950. Thermal design of livestock shades. Agric. Eng. 31:601-606.

Kimmel, E., H. Arki, D. Broday, and A. Berman. 1991. A model of evaporative cooling in a wetted hide. J. Agric. Eng. Res. 49:227-241.

Landsberg, J. J., B. White, and M. R. Thorpe. 1979. Computer analysis of the efficacy of evaporative cooling for glasshouses in high energy environments. J. Agric. Eng. Res. 24:29-39.

McArthur, A. J. 1987. Thermal interaction between animal and microclimate: A comprehensive model. J. Theor. Biol. 126:203-238.

McGovern, R. R., and J. M. Bruce. 2000. A model of the thermal balance for cattle in hot conditions. J. Agric. Eng. Res. 77:91-92.
Monteith, J. L. 1973. Principles of Environmental Physics. Edward Arnold, London, UK.

Overton, M. W., W. M. Sischo, G. D. Temple, and D. A. Moore. 2002. Using time-lapse video photography to assess dairy cattle lying behavior in a free-stall barn. J. Dairy Sci. 85:2407-2413.

Ryan, D. P., M. P. Boland, E. Kopel, D. Armstrong, L. Munyakazi, R. A. Godke, and R. H. Ingraham. 1992. Evaluating two different evaporative cooling management systems for dairy cows in a hot, dry climate. J. Dairy Sci. 75:1052-1059.

Seath, D. M., and G. D. Miller. 1948. Effect of water sprinkling with and without air movement on cooling dairy cows. J. Dairy Sc. 31:361-366.

Shultz, T. A. 1984. Weather and shade effects on corral cow activities. J. Dairy Sci. 67:868-873.

Singletary, I. B., R. W. Bottcher, and G. R. Baughman. 1996. Characterizing effects of temperature and humidity on misting evaporative efficiency. Trans. ASAE 39:1801-1809.

Stevens, D. G. 1981. A model of respiratory vapor loss in Holstein dairy cattle. Trans. ASAE 24:151-153.

Timmons, M. B., and G. R. Baughman. 1983. Experimental evaluation of poultry mist-fogging systems. Trans. ASAE 26:207-210.

Wiersma, F., and G. H. Stott. 1966. Microclimate modifications for hot weather stress relief of dairy cattle. Trans. ASAE 9:309-311.

Wilson, J. L., H. A. Hughes, and W. D. Weaver. 1983. Evaporative cooling with fogging nozzles in broiler houses. Trans. ASAE 26:557-561. 